\title{
Reversing an extracellular electron transfer pathway for electrode-driven NADH generation
}

Nicholas M. Tefft ${ }^{1}$ and Michaela A. TerAvest ${ }^{1 *}$

$5 \quad{ }^{1}$ Department of Biochemistry and Molecular Biology, Michigan State University, East Lansing, MI, USA

$6 \quad *$ corresponding author

7 Address: 603 Wilson Rd., East Lansing, MI, 48823 Email: teraves2@msu.edu

\section{Abstract}

Microbial electrosynthesis is an emerging technology with the potential to simultaneously store renewably generated energy, fix carbon dioxide, and produce high-value organic compounds. However, limited understanding of the route of electrons into the cell remains an obstacle to developing a robust microbial electrosynthesis platform. To address this challenge, we engineered an inward electron transfer pathway in Shewanella oneidensis MR-1. The pathway uses native Mtr proteins to transfer electrons from an electrode to the inner membrane quinone pool. Subsequently, electrons are transferred from quinones to $\mathrm{NAD}^{+}$by native NADH dehydrogenases. This reverse functioning of NADH dehydrogenases is thermodynamically unfavorable, therefore we have added a light-driven proton pump (proteorhodopsin) to generate proton-motive force to drive this activity. Finally, we use reduction of acetoin to 2,3-butanediol via a heterologous butanediol dehydrogenase (Bdh) as an electron sink. Bdh is an NADHdependent enzyme, therefore, observation of acetoin reduction supports our hypothesis that cathodic electrons are transferred to intracellular $\mathrm{NAD}^{+}$. Multiple lines of evidence indicate proper functioning of the engineered electrosynthesis system: electron flux from the cathode is influenced by both light and acetoin availability; and 2,3-butanediol production is highest when both light and a poised electrode are present. Using a hydrogenase-deficient S. oneidensis

27 background strain resulted in a stronger correlation between electron transfer and 2,3-butanediol production, suggesting that hydrogen production is an off-target electron sink in the wild-type 
29 background. This system represents a promising genetically engineered microbial

30 electrosynthesis platform and will enable a new focus on synthesis of specific compounds using

31 electrical energy.

\section{Introduction}

33 Microbial electrosynthesis is a technology that utilizes microbes for production of useful

34 chemicals using carbon dioxide, water, and electricity as feedstocks (1). While most microbial

35 electrosynthesis efforts to date have targeted fuel production, other possible applications include

36 production of platform chemicals or bioplastics (2). With pressure to develop sustainable

37 production systems, microbial electrosynthesis is an attractive technology to simultaneously produce valuable products and store electricity generated by wind and solar technologies. Initial

39 efforts have focused on three primary platforms for microbial electrosynthesis: pure cultures of acetogens $(3,4)$; undefined mixed cultures $(5,6)$; and electron shuttles paired with model

41 bacterial strains $(7,8)$. While these approaches have demonstrated proof-of-concept, significant

42 improvements in product yield and product spectrum are necessary to make microbial

43 electrosynthesis economically viable.

44 Pure culture microbial electrosynthesis systems have been developed in an effort to 45 understand the mechanism of electron uptake from a cathode. These systems primarily utilize 46 acetogenic bacteria because they are naturally capable of converting carbon dioxide into acetate 47 using hydrogen or other inorganic electron donors $(9,10)$. Multiple reports show that acetogens 48 are capable of using an electrode in place of native electron donors $(3,4)$. While acetate is a 49 relatively low value product, genetic modification may yield strains capable of producing other 50 compounds through electrosynthesis (11). While this is a promising approach, significant 51 challenges to acetogen engineering remain, and further developments are necessary $(11,12)$. An 
52 alternative approach that may yield specific products is to utilize chemical electron mediators to

53 transfer electrons from an electrode into existing model organisms. This approach has been

54 successful in multiple organisms to generate products such as succinate and ethanol $(7,13-15)$.

55 However, the cost of the mediator and downstream separations likely make this approach too costly for industrial scale up.

Mixed culture approaches to microbial electrosynthesis have also borne success, due to their ability to generate a range of products without genetic modification. Early efforts in this area have primarily generated acetate, with adjustments to operating conditions driving increased 60 yield (16-18). However, other molecules can also be produced, including butyrate, butanol, and

61 ethanol $(5,19)$. Selective enrichment of the community is important to improve yields and

62 product specificity $(6,17)$. While evidence that higher value products are attainable increases the 63 attractiveness of electrosynthesis using undefined mixed cultures, off-target production remains

64 problematic. For example, increased abundance of methanogens over time has posed difficulties

65 for long term experiments due to decreased acetate titers and increased methane production (6,

66 20). Further, a mixed community cannot be engineered to produce a specific high-value

67 compound with any current technology.

Overall, optimization of existing approaches to microbial electrosynthesis has been

69 hampered by poorly defined interactions between bacteria and cathode electrodes. In most cases,

70 the mechanism of electron transfer is unknown, although in mixed culture systems, $\mathrm{H}_{2}$ is

71 recognized as a major electron carrier between the electrode and microbes (5). For pure cultures,

72 direct electron transfer has been proposed, but not proven $(3,4)$. Similarly, specific mechanisms

73 of electron transfer via chemical mediators are only beginning to be investigated (13). In

74 contrast, transmembrane electron transfer is much better understood between dissimilatory metal 
75 reducing bacteria and anode electrodes. Shewanella oneidensis MR-1 is particularly well

76 understood and the structure of the Mtr pathway and its function in transferring electrons to the

77 outer surface of the cell have been thoroughly described in the last two decades (21-28).

78 The well understood electron transfer mechanism of Shewanella makes it an excellent

79 candidate to engineer a microbial electrosynthesis system from the ground up using synthetic

80 biology tools. Initial steps to explore the use of $S$. oneidensis MR-1 for microbial

81 electrosynthesis have demonstrated reverse electron transfer through the Mtr pathway. Ross et al.

82 (29) showed electron transfer from a cathode to $S$. oneidensis MR-1 with fumarate as an electron

83 sink, indicating that the Mtr pathway can transfer electrons from a cathode to respiratory

84 quinones. More recent work by Rowe et al. (30) has demonstrated that S. oneidensis MR-1 can

85 also catalyze electron transfer from a cathode to oxygen through the Mtr pathway and the 86 quinone pool.

While previous work has demonstrated the ability to generate reduced quinones via a cathode, this is not sufficient to power intracellular reduction reactions. Electrons in the quinone pool have too positive a redox potential to be spontaneously transferred to $\mathrm{NAD}^{+}$(ca. $-80 \mathrm{mV}_{\mathrm{SHE}}$

90 for menaquinone:menaquinol vs. ca. $-320 \mathrm{mV}$ for $\mathrm{NAD}^{+}: \mathrm{NADH}$ ) and have only been transferred

91 to electron acceptors with a more positive redox potential, such as fumarate (ca. $\left.+30 \mathrm{mV} \mathrm{V}_{\mathrm{SHE}}\right)$.

92 Electrons should ideally be transferred to an intracellular, lower potential electron carrier to be

93 useful for electrosynthesis. NADH is a promising intracellular electron carrier to target because it

94 is involved in many metabolic reactions and is relatively accessible from the quinone pool

95 through NADH dehydrogenases. Under typical conditions, NADH dehydrogenases catalyze the

96 favorable transfer of electrons from NADH to quinones and conserve energy as a proton-motive

97 force (31). However, NADH dehydrogenases may also catalyze the reverse redox reaction, 
98

99

100

101

102

103

104

105

106

107

108

109

110

111

112

113

114

115

116

117

118

utilizing proton-motive force as an energy source, as observed in purple photosynthetic bacteria (32).

Based on previous work and our knowledge of S. oneidensis MR-1 metabolism, we hypothesized that NADH dehydrogenases could be driven in reverse to transfer electrodederived electrons into the cell. Therefore, we engineered a system relying on the native Mtr pathway and NADH dehydrogenases to catalyze the electron transfer steps and using a heterologous light-driven proton pump to generate proton motive force (PMF) to drive NADH dehydrogenases in reverse (Figure 1). We expressed butanediol dehydrogenase and provided its substrate, acetoin, to provide an electron sink and a mechanism to track NADH generation. This system represents a generalizable platform to use cathodes to drive NADH-dependent reductions in S. oneidensis MR-1. Further development of this platform could lead to a new capability to generate specific, high-value compounds using electricity and carbon dioxide as feedstocks.

\section{Results and Discussion}

\section{Development of modified $S$. oneidensis strains}

Genes encoding proteorhodopsin (PR) and butanediol dehydrogenase (Bdh) were cloned into a medium copy plasmid with a constitutive promoter and conjugated into S. oneidensis (both WT and a strain lacking hydrogenases; $\triangle h y a B \Delta h y d A$ ) (Table 1). A FLAG tag was added to the Cterminus of each protein to facilitate detection by Western blot. Both proteins were detectable in cleared lysates using an anti-FLAG antibody, confirming successful expression (Figure S1). To confirm function of Bdh, the modified strain was grown aerobically in the presence of $15 \mathrm{mM}$ exogenous acetoin in LB. Accumulation of 2,3-butanediol was observed by HPLC, indicating 
120 that the expressed Bdh is functional (Figure S2). Function of PR expressed from a similar

121 plasmid was previously demonstrated in S. oneidensis MR-1 $(33,34)$.

123 Light and current drive a target reduction reaction in modified $S$. oneidensis

124 To determine the capability of the engineered cells to accept electrons from a cathode, the strain

125 lacking hydrogenases and carrying a plasmid with PR and Bdh was pre-grown and inoculated 126 into bioelectrochemical systems at a final density of $\mathrm{OD}_{600}=0.17$. This mutant strain was used to

127 ensure that $\mathrm{H}_{2}$ did not act as a mediator between cells and the electrode. This mutant was

128 previously shown to lack the ability to produce or consume $\mathrm{H}_{2}(35,36)$. To minimize the

129 influence of organic carbon as an electron donor, the bioelectrochemical systems initially

130 contained oxygen (ambient) and the working electrode was set at an anodic potential $(+0.4$

$131 \mathrm{~V}_{\mathrm{SHE}}$ ). This was done to decrease the availability of organic carbon by oxidizing stored organic

132 material and media components carried over during inoculation. After 6 hours, the working

133 electrode was switched to a cathodic potential ( $\left.-0.3 \mathrm{~V}_{\mathrm{SHE}}\right)$, and $\mathrm{N}_{2}$ sparging was used to remove

134 oxygen from the bioreactors. Each bioelectrochemical system was equipped with green LED

135 lights around the working electrode chamber to drive proton pumping by PR (Figure S3). After

136 switching to the working electrode to a cathodic potential, a stable cathodic current between -5

137 and $-8 \mu \mathrm{A}$ was observed. After 16 hours, an anoxic acetoin solution was injected into each

138 bioreactor to a final concentration of $10 \mathrm{mM}$. After acetoin injection, an increase of -12 to -18

$139 \mu \mathrm{A}$ was observed in all bioelectrochemical systems (Figure 2). Note that for cathodic current, a 140 greater negative current represents a greater amount of electron transfer.

142 with and without functional PR by pre-growing the strain with or without the essential PR 
143 cofactor, all-trans-retinal. We refer to PR with retinal as holo-PR and PR without retinal as apo-

144 PR. Cathodic current was significantly higher, $(p=0.03)$ in systems with holo-PR (Figure 3). We

145 confirmed that the increased current was due to PR activity by turning off the LED lights

146 attached to the bioreactor. When the lights were turned off, cathodic current generated by cells

147 with holo-PR decreased, while cells with apo-PR were unaffected (Figure 3). This supports the

148 model that the effect of light is dependent on functional PR; if the effect of light was due to

149 heating or interaction of light with native components, we would expect cells with apo-PR to

150 have a similar response to cells with holo-PR. The dependence of current on holo-PR and light

151 supports our hypothesis that enhanced PMF generation by PR promotes electron uptake by the

152 modified strain.

During the same experiment, we also measured 2,3-butanediol accumulation to determine

154 whether cathodic electrons were directed toward the target reaction, acetoin reduction. As with

155 current, 2,3-butanediol accumulation was greater in the bioelectrochemical systems with holo-PR

156 (Figure 4). Based on the total charge transfer over the course of 6 days, accumulation of $0.17 \pm$

$157 \quad 0.02 \mathrm{mM}$ 2,3-butanediol was expected by the end of the experiment. Accumulation of $0.19 \pm$

$158 \quad 0.01 \mathrm{mM}$ 2,3-butanediol was actually observed. The experiment was repeated using the same

159 conditions, with the exception that the electrode was disconnected from the potentiostat. This

160 experiment confirmed that acetoin reduction was driven by the electrode (Figure 4). Indeed, 2,3-

161 butanediol production was significantly reduced when the electrode was not poised $(\mathrm{p}=0.01)$, and

162 accumulation of only $0.13 \pm 0.00 \mathrm{mM}$ was observed. Based on our observations, $0.06 \mathrm{mM}$ of the

163 2,3-butanediol (32\% of total production) was generated through the electrode-dependent process.

164 We hypothesize that 2,3-butanediol was not completely eliminated when the electrode was not

165 poised because remaining organic carbon from the inoculum could be oxidized to generate the 
NADH needed for acetoin reduction. Although we attempted to remove as much organic carbon from the experiment as possible, some cells may have lysed during the washing and inoculation process, thus providing organics to the surviving cells.

171 expressed, no 2,3-butanediol was detectable in the bioreactors after 6 days, and cathodic current

172 was significantly reduced, $(\mathrm{p}=0.02)$. The strain without Bdh generated ca. $-11 \mu \mathrm{A}$ when holo-PR

173 was present (Figure 5), representing a ca. 32\% reduction in electron transfer compared to the

174 strain with Bdh. This indicates that full activity of the inward electron transfer system is

175 dependent on acetoin reduction, although there is also some Bdh-independent electron transfer.

176 This experiment also allows us to refine our comparisons between charge transfer and 2,3-

177 butanediol accumulation. By subtracting the total charge transfer catalyzed by the strain without

178 Bdh from the strain with Bdh, we can calculate the amount of charge transfer that is Bdh-

179 dependent. We calculate that $0.03 \mathrm{mM}$ of 2,3-butanediol accumulation is expected based on the amount of Bdh-dependent electron transfer. This amount of charge transfer agrees well with the

$1810.06 \mathrm{mM}$ of electrode-dependent 2,3-butanediol accumulation that we observed.

183 present, indicating that the Bdh-independent process requires PMF generation. This may indicate

184 that the Bdh-independent process also relies on reverse activity of NADH dehydrogenases,

185 although we do not yet know the eventual fate of electrons transferred to the cells without Bdh.

186 No other typical metabolic byproducts of S. oneidensis MR-1 (e.g., acetate, formate) were

187 detectable by our HPLC analysis. 
$\underline{\text { Hydrogen is an electron sink for inward electron transfer }}$

190 A common question in previous work on microbial electrosynthesis is whether $\mathrm{H}_{2}$ mediates

191 electron transfer, because it can be produced abiotically at the cathode (37). Because small

192 amounts of hydrogen are difficult to measure and may be scavenged quickly by cells on the

193 electrode, it has been challenging to rule out hydrogen as a mediator. We have attempted to do so

194 using an approach similar to Deutzmann et al. (38), i.e., by using a hydrogenase mutant strain.

195 The strain we used does not have the ability to use molecular hydrogen as an electron source or

$196 \operatorname{sink}(35,36,39)$. To determine whether a hydrogen mediated pathway would function when

197 hydrogenases were present, we also performed the experiments described above in a wild-type

198 background. (Note: these experiments were performed without the initial oxic/anodic step, see

199 Methods for details.) When hydrogenase activity was present, overall current increased while

200 2,3-butanediol accumulation decreased (Figure 6). This indicates that rather than acting as a

201 mediator, $\mathrm{H}_{2}$ was an electron sink for $\mathrm{S}$. oneidensis on the cathode. If hydrogen acted as a

202 mediator in this system, we would expect a simultaneous increase in both current and 2,3-

203 butanediol when hydrogenases were present. Our results indicate that cells with hydrogenases

204 generated $\mathrm{H}_{2}$ and that when the pathway to hydrogen was cut off, electrons were directed more

205 efficiently toward acetoin reduction.

206

207 Comparison with previous work

208 Our results represent an advance in the field of microbial electrosynthesis because we have

209 engineered a pathway to generate intracellular reducing power with a detailed understanding of

210 the electron transfer mechanism. The transmembrane electron conduit connecting the quinol pool

211 to electrodes has been very well characterized $(21-23,28,40)$ and is known to be reversible $(29$, 
212 41). We hypothesized that we could take inward electron transfer in S. oneidensis MR-1 one step

213 further by utilizing PMF to overcome the thermodynamic barrier of the quinol:NAD ${ }^{+}$reduction

214 and an excess of electron sink (Bdh/acetoin) to avoid over reduction of the $\mathrm{NAD}^{+}$:NADH pool.

215 The results presented here support that hypothesis; we have shown that electron transfer to the

216 target reaction is dependent on the electrode and on each of the modifications made to the strain.

217 Further, the target reaction is NADH-dependent, indicating that we have successfully connected

218 the electrode to the intracellular NADH pool.

While the system described here is one of the best understood inward electron transfer

220 demonstrations to date, there is still more to learn. One critical knowledge gap is exactly how

221 electrons are transferred from the quinol pool to NADH. The S. oneidensis MR-1 genome

222 encodes four NADH:quinone oxidoreductases and any of them could be involved in inward

223 electron transfer $(42,43)$. However, because we have observed dependence of inward electron

224 transfer on PMF, we hypothesize that the proton-coupled NADH dehydrogenase, Nuo, is a major

225 contributor to inward electron transfer. Future studies with Nuo deletion strains will enable us to

226 elucidate the link between respiratory quinones and NADH in our system.

In this study, we have successfully driven a heterologous reduction reaction inside living

228 bacteria using an extracellular electrode as the electron source. Rather than using native

229 capabilities of acetogenic bacteria, we engineered a metal-reducing organism to reverse the flow

230 of electrons in its respiratory chain. This represents a proof of concept for an engineered

231 microbial electrosynthesis pathway, and with further development this platform can be used to

232 upgrade bioproducts through electrofermentation or to fix $\mathrm{CO}_{2}$. Because electrical energy is one

233 of the inputs to the system, the organic molecules produced also represent storage of electrical

234 energy. This type of storage strategy will become essential as wind and solar power capacity 
235 increase. Wind and solar energy are intermittent sources; therefore, robust energy storage

236 methods are critical. While significant improvements in engineered microbial electrosynthesis

237 must still be made, a critical mass of researchers forming around this concept will help propel

238 Shewanella based electrosynthesis toward real world application.

239

240 Methods

$241 \quad$ Bacterial strains, plasmids, and growth conditions

242 Strains and plasmids used in this study are listed in Table 1. E. coli strains were grown at $37^{\circ} \mathrm{C}$

243 and $S$. oneidensis strains at $30^{\circ} \mathrm{C}$, both with shaking at $250 \mathrm{rpm}$. Strains were grown in $\mathrm{LB}$

244 medium (Miller, Accumedia) for assembly and initial verification of strains. Strains bearing

245 pBBR1-MCS2-derived plasmids were grown with a final concentration of $50 \mu \mathrm{g} / \mathrm{mL}$ kanamycin.

246 Pre-cultures for bioelectrochemical experiments were grown in M5 minimal medium: $1.29 \mathrm{mM}$

$247 \quad \mathrm{~K}_{2} \mathrm{HPO}_{4}, 1.65 \mathrm{mM} \mathrm{KH}_{2} \mathrm{PO}_{4}, 7.87 \mathrm{mM} \mathrm{NaCl}, 1.70 \mathrm{mM} \mathrm{NH}_{4} \mathrm{SO}_{4}, 475 \mu \mathrm{M} \mathrm{MgSO} \cdot 7 \mathrm{H}_{2} \mathrm{O}, 10 \mathrm{mM}$

248 HEPES, $0.01 \%(\mathrm{w} / \mathrm{v})$ casamino acids, $1 \mathrm{X}$ Wolfe's mineral solution (Al was not included), and

249 1X Wolfe's vitamin solution (riboflavin was not included), $\mathrm{pH}$ adjusted to 7.2 with $5 \mathrm{M} \mathrm{NaOH}$.

250 M5 medium was supplemented with D,L-lactate to a final concentration of $20 \mathrm{mM}$. M5 medium

251 with the following modifications was used in the working electrode chamber during

252 bioelectrochemical experiments: $100 \mathrm{mM}$ HEPES, no carbon source, no casamino acids, $1 \mu \mathrm{M}$

253 riboflavin.

255 Design and assembly of Bdh and Bdh-PR plasmids

256 The gene sequence encoding butanediol dehydrogenase in Enterobacter cloacae was

257 downloaded from the NCBI gene database (NCBI Reference NC_014121.1). The codon usage 
258

259

260

261

262

263

264

265

266

267

268

269

270

271

272

273

274

275

276

277

278

279

280

was optimized for S. oneidensis MR-1 using JCAT Codon Adaptation Tool (www.jcat.de). A FLAG tag (44) was added immediately before the stop codon and the Salis lab RBS calculator (45) was used to design an optimized RBS for the Bdh-FLAG sequence. Sequences of 20 base pairs flanking the target SmaI restriction sites in the pBBR1-MCS2 sequence were added as flanking regions on the codon optimized RBS-Bdh-FLAG sequence for use in assembly. The entire sequence was submitted to Integrated DNA Technologies for synthesis as a gBlock gene fragment. The same general procedure was utilized to add the gene coding for proteorhodopsin to the plasmid containing $b d h$.

We isolated pBBR1-MCS2 plasmid DNA from E. coli using an E.Z.N.A plasmid DNA kit (Omega Bio-Tek). Prepared plasmid DNA was linearized using SmaI (New England Biolabs, Ipswich, MA) digestion for 4 hours at $25^{\circ} \mathrm{C}$. The synthesized RBS-Bdh-FLAG insert was resuspended in water to a final concentration of $10 \mathrm{ng} / \mu \mathrm{L}$ and was assembled with linearized pBBR1-MCS2 plasmid using NEBuilder High Fidelity DNA assembly kit (New England Biolabs) using $50 \mathrm{ng}$ of pBBR1-MCS2 and $100 \mathrm{ng}$ of RBS-Bdh-FLAG insert. Assembled pBBR1-MCS2-Bdh was transformed into E. coli Mach1 chemically competent cells (Invitrogen). pBBR1-MCS2-Bdh-PR was prepared as above except pBBR1MCS2-Bdh was digested using NdeI and SpeI (New England Biolabs, Ipswich, MA) for 3 hours at $37^{\circ} \mathrm{C}$ prior to assembly with the synthesized PR gene. Transformants were initially screened via PCR using M13 forward and reverse primers and then sequenced (Sanger sequencing, RTSF Genomics Core, Michigan State University) to verify proper assembly and transformation. Verified Bdh and Bdh-PR plasmids were transformed into chemically competent $E$. coli WM3064 for use in conjugation with $S$. oneidensis. Conjugation was performed using a standard protocol for S. oneidensis MR-1 (46). 
282 Expression of Bdh and PR were verified via Western blot through use of FLAG tags added

283 during gene synthesis. Cells were cultured in $5 \mathrm{~mL}$ of LB for 16 hours before $200 \mu \mathrm{L}$ was

284 centrifuged for 2 minutes at 10,000 rpm. Supernatant was removed, and cells were resuspended

285 in $200 \mu \mathrm{L}$ of a mixture of $1 \mathrm{~mL}$ Laemmli buffer, $20 \mu \mathrm{L}$ of concentrated bromophenol blue (JT

286 Baker, D29303) in 5X Laemmli buffer, and $10 \mu \mathrm{L}$ of 1 M DTT. Cells were vortexed to mix and

287 incubated at $95^{\circ} \mathrm{C}$ for 10 minutes. A mini-PROTEAN tetra cell electrophoresis chamber (Biorad,

288 1658005EDU) was loaded with $1 \mathrm{X}$ TGS buffer. Samples were vortexed a $5 \mu \mathrm{L}$ was loaded onto

289 a mini-protean TGX stain free gel (Biorad, 4568095) alongside $5 \mu \mathrm{L}$ of Precision Plus ladder

290 (Biorad, 1610376).

Samples were run at $100 \mathrm{~V}$ for 1.5 hours until dye front moved off the gel. The gel

292 cassette was broken, and gel removed to 1X Transfer buffer (Biorad, 10026938). Proteins were

293 then transferred to a nitrocellulose membrane (Biorad, 1704270) using a Biorad Turbo transfer

294 system (Biorad, 1704150). The membrane was rinsed with $30 \mathrm{~mL}$ TBST buffer, this buffer was

295 discarded, and the membrane was blocked using $50 \mathrm{~mL}$ of $3 \%$ BSA TBST buffer for 1 hour on

296 an orbital shaker. Blocking solution was discarded and replaced with $30 \mathrm{~mL}$ of 3\% BSA TBST

297 buffer then $7.8 \mu \mathrm{L}$ of $3.85 \mathrm{mg} / \mathrm{mL}$ anti-FLAG antibody (Sigma-Aldrich, F3165) was added. The

298 membrane was then incubated for 16 hours at $4^{\circ} \mathrm{C}$, on an orbital shaker.

299

The membrane was then rinsed for 5 minutes with TBST buffer three times. After rinsing

$30030 \mathrm{~mL}$ of $3 \%$ BSA TBST buffer with $0.0625 \mu \mathrm{L}$ of anti-mouse antibody (Sigma-Aldrich, A9044)

301 was added. The membrane was incubated for 1 hour at RT. Buffer was discarded and the 
enhancer solution, then adding the entire volume to the membrane. The membrane was incubated for 5 minutes, the ECL solution was discarded and the membrane was imaged using a Kodak 4000R image station and Caresteam Molecular Imaging software.

\section{$\underline{\text { Bioelectrochemical system construction and operation }}$}

Bioelectrochemical measurements were performed in custom two-chambered bioreactors separated by a cation exchange membrane (Membranes International, CMI-7000S) cut in a 4.5 $\mathrm{cm}$ circle, to completely cover the $15 \mathrm{~mm}$ opening connecting working and counter chambers. Working electrodes were prepared from carbon felt (Alfa Aesar, 43200RF) cut into 50x25 mm rectangles and adhered to a titanium wire using carbon adhesive (Sigma-Aldrich, 09929-30G) and allowed to dry for 16 hours. Reference electrodes were prepared by oxidizing silver wires electrochemically in a dilute $\mathrm{KCl}$ solution and fixing them in saturated $\mathrm{KCl}$-agar in a custommade glass housing. The housing maintained ionic connection between the reference electrode and working chamber via a magnesia frit (Sigma-Aldrich, 31408-1EA). Counter electrodes were graphite rods $1 / 8$ " in diameter (Electron Microscopy Science, 07200) suspended in the counter chamber filled with PBS. Working chambers were filled with $140 \mathrm{~mL}$ of M5 medium (100 mM HEPES, no Casamino acids) prior to autoclaving. After autoclaving, $1.7 \mathrm{~mL} 100 \mathrm{X}$ vitamin stock, $1.7 \mathrm{~mL}$ Wolfe's minerals (no Al), $0.17 \mathrm{~mL} 50 \mathrm{mg} / \mathrm{mL}$ kanamycin, and $0.85 \mathrm{~mL} 0.2 \mathrm{mM}$ riboflavin were added to working chamber.

Reactors were connected to a potentiostat (VMP, BioLogic USA) and the working electrode poised at $+0.4 \mathrm{~V}_{\text {SHE}}$. Current was measured every 1 second for the duration of the experiment. Current measurements were collected for at least 16 hours prior to inoculation. Reactors were inoculated with cultures grown in $50 \mathrm{~mL}$ M5 medium supplemented with $20 \mathrm{mM}$ 
D, L-lactate. Cultures were grown in $250-\mathrm{mL}$ flasks at $30^{\circ} \mathrm{C}$ for 17 hours shaking at $275 \mathrm{rpm}$.

328 After 17 hours, $25 \mu \mathrm{L} 20 \mathrm{mM}$ all-trans-retinal (vitamin A aldehyde, Sigma-Aldrich, R2500), the essential proteorhodopsin cofactor (47), was added to designated flasks for functional PR testing to a final concentration of $10 \mu \mathrm{M}$ and all flasks were returned to incubator, shaking, for 1 hour. culture volumes were prepared for each reactor. Absorbance at $600 \mathrm{~nm}$ was determined for each culture using a biophotomer (Eppendorf, D30) before the volume was transferred to a $50 \mathrm{~mL}$ conical tube (VWR, 89039-664) and centrifuged for 5 minutes at 10,000 rpm (Thermo Scientific ST8R; Rotor: 75005709). Supernatant was removed, and a second volume of cells was added to the conical tube containing the cell pellet before a second centrifugation step. Supernatant was

337 removed, and the combined pellets were resuspended in $10 \mathrm{~mL}$ of M5 (100 mM HEPES). 
350 cycling was performed at 24 hours post acetoin injection, lights were turned off for 1 hour

351 followed by 1 hour on. Light cycles at 24 hours were repeated three times, after which lights

352 were left on.

Samples were regularly removed from the bioreactors for determination of $\mathrm{OD}_{600}$ and

354 HPLC analysis. A 2-mL sample was taken approximately every 24 hours using a $21 \mathrm{~g}$ needle

355 (Beckton Dickson, 305167) and 3-mL syringe (Beckton Dickson, 309657). One mL was used for

356 determination of $\mathrm{OD}_{600}$. One $\mathrm{mL}$ was transferred to a micro-centrifuge tube (VWR, 20170-038)

357 and frozen at $-20^{\circ} \mathrm{C}$ until preparation for HPLC analysis. Experiments without a set potential on

358 the working electrode were set up as above except, immediately after acetoin injection the

359 potentiostat was disconnected from the working electrodes.

360 Experiments testing for the effect of hydrogenase activity (Figure 6) were performed as

361 above expect as follows. Potential was set to $-0.3 \mathrm{~V}_{\text {SHE }}$ during background data collection and no

362 anodic potential was used. Oxygen removal using $\mathrm{N}_{2}$ gas was also started during background

363 data collection and continued for the entire experiment. Cultures grown for reactor inoculation

364 were standardized to the lowest observed $\mathrm{OD}_{600}$ after 18 hours of growth, instead of a target OD

365 of 3.6. Finally, acetoin was injected two hours after inoculation once a stable base line current

366 was achieved.

HPLC Analysis

369 HPLC analysis was performed on a Shimadzu 20A HPLC, using an Aminex HPX-87H (BioRad,

370 Hercules, CA) column with a Micro-guard Cation $\mathrm{H}^{+}$guard column (BioRad, Hercules, CA) at

$37165^{\circ} \mathrm{C}$. Compounds of interest were separated using a $0.6 \mathrm{~mL} / \mathrm{min}$ flow rate, in $5 \mathrm{mM}$ sulfuric acid

372 with a 30-minute run time. Eluent was prepared by diluting a 50\% HPLC-grade sulfuric acid 
373 solution (Fluka) in Milli-Q water and degassing the solution at $37^{\circ} \mathrm{C}$ for $3-5$ days before use.

374 Compounds of interest were detected by a refractive index detector (Shimadzu, RID-20A)

375 maintained at $60^{\circ} \mathrm{C}$. Samples were prepared by centrifuging $1-\mathrm{mL}$ samples taken from the

376 working electrode chambers for 10 minutes at 13,000 rpm in a microcentrifuge (Minispin Plus,

377 Eppendorf) to remove cells. The supernatant was removed and transferred to a 2.0-mL glass

378 HPLC vial (Vial: Restek, 21140; Cap: JG Finneran, 5395F09). Mixed standards of 2,3-

379 butanediol and acetoin were prepared at concentrations of 1, 2, 5, 10, and $15 \mathrm{mM}$. Samples were

380 maintained at $10^{\circ} \mathrm{C}$ by an auto-sampler (Shimadzu, SIL-20AHT) throughout analysis. Acetoin

381 and 2,3-butanediol concentrations in the samples were determined using linear calibration curves

382 based on the external standards.

\section{$\underline{\text { Data analysis }}$}

385 Analysis of HPLC and current data was performed using Rstudio using the following packages:

386 ggplot2 (48), reshape2 (49), dplyr (50), and TTR (51).

\section{Acknowledgements}

389 The authors thank Dr. Jeffrey Gralnick (University of Minnesota) for providing a plasmid

390 containing the PR gene and Dr. N. Cecilia Martinez Gomez for helpful comments on the

391 manuscript. This work was partially funded by NSF CAREER award 1750785. This work was

392 also supported by the USDA National Institute of Food and Agriculture, Hatch project 1009805. 
Tables and Figures

Table 1. Strains and plasmids used in this study

E. coli

Mach1

WM3064

S. oneidensis

MR-1

$\triangle h y a B \Delta h y d A$

Plasmids

pBBR1-MCS2

pBBR1-PR

pBdh

pBdh-PR
Host strain for plasmids

Conjugation strain for $S$. oneidensis

Wild Type

Hydrogenase double knockout mutant

Kan resistance, broad host vector

pBBR1MCS2 bearing proteorhodopsin [uncultured marine gamma proteobacterium EBAC31A08]

pBBR1MCS2 bearing butanediol dehydrogenase gene from Enterobacter cloacae

pBBR1MCS2 bearing butanediol dehydrogenase from Enterobacter cloacae and proteorhodopsin [uncultured

This study

This study marine gamma proteobacterium EBAC31A08]

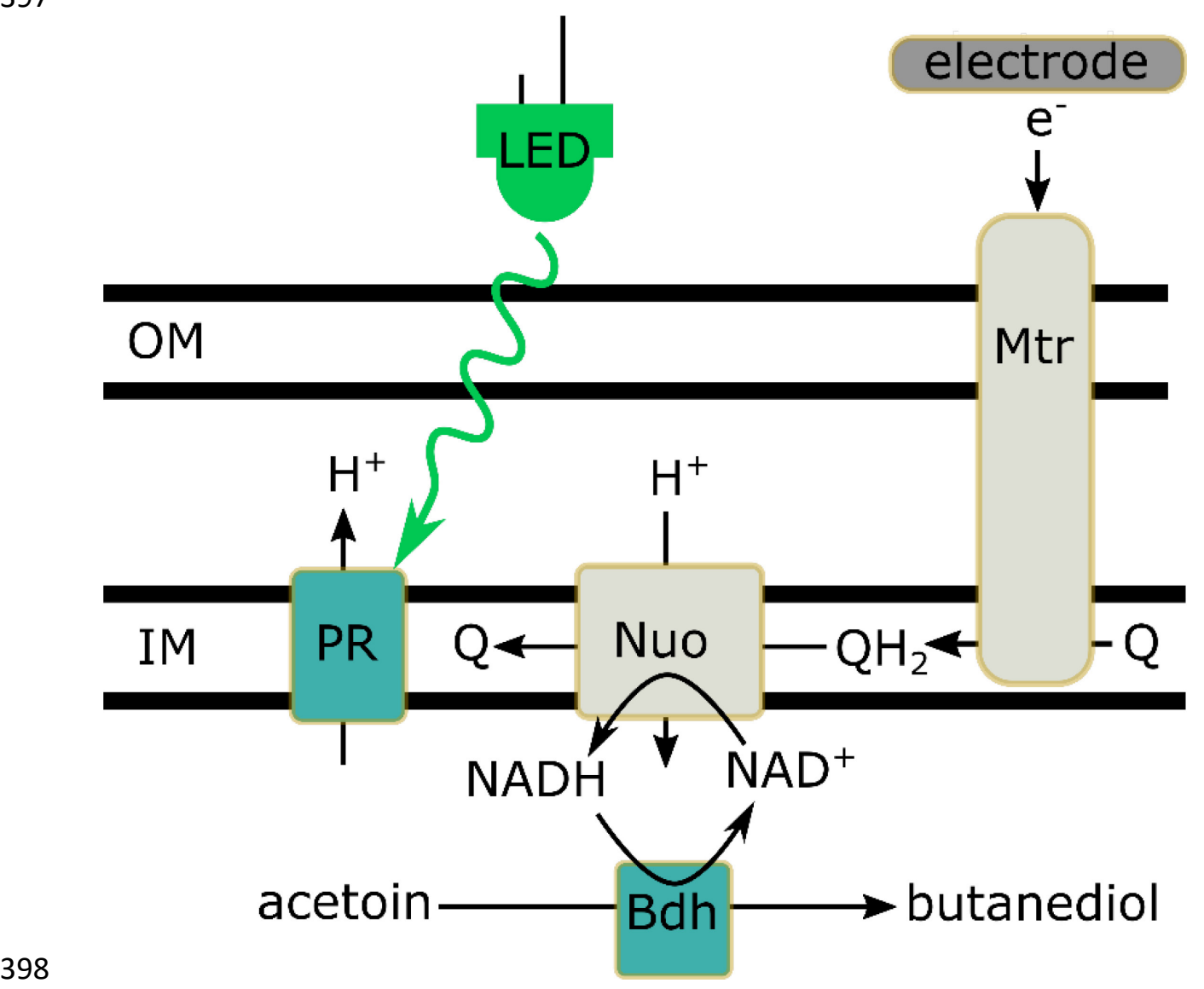


Figure 1. Engineered inward electron transfer pathway. Shewanella oneidensis MR-1 pathway designed to transfer electrons from the electrode to $\mathrm{NAD}^{+}$to generate intracellular reducing equivalents. Native proteins are shown in grey, heterologous proteins are shown in green. OM: outer membrane; IM: inner membrane; LED: green light source. Nuo is one of four NADH dehydrogenases encoded in the S. oneidensis MR-1 genome.

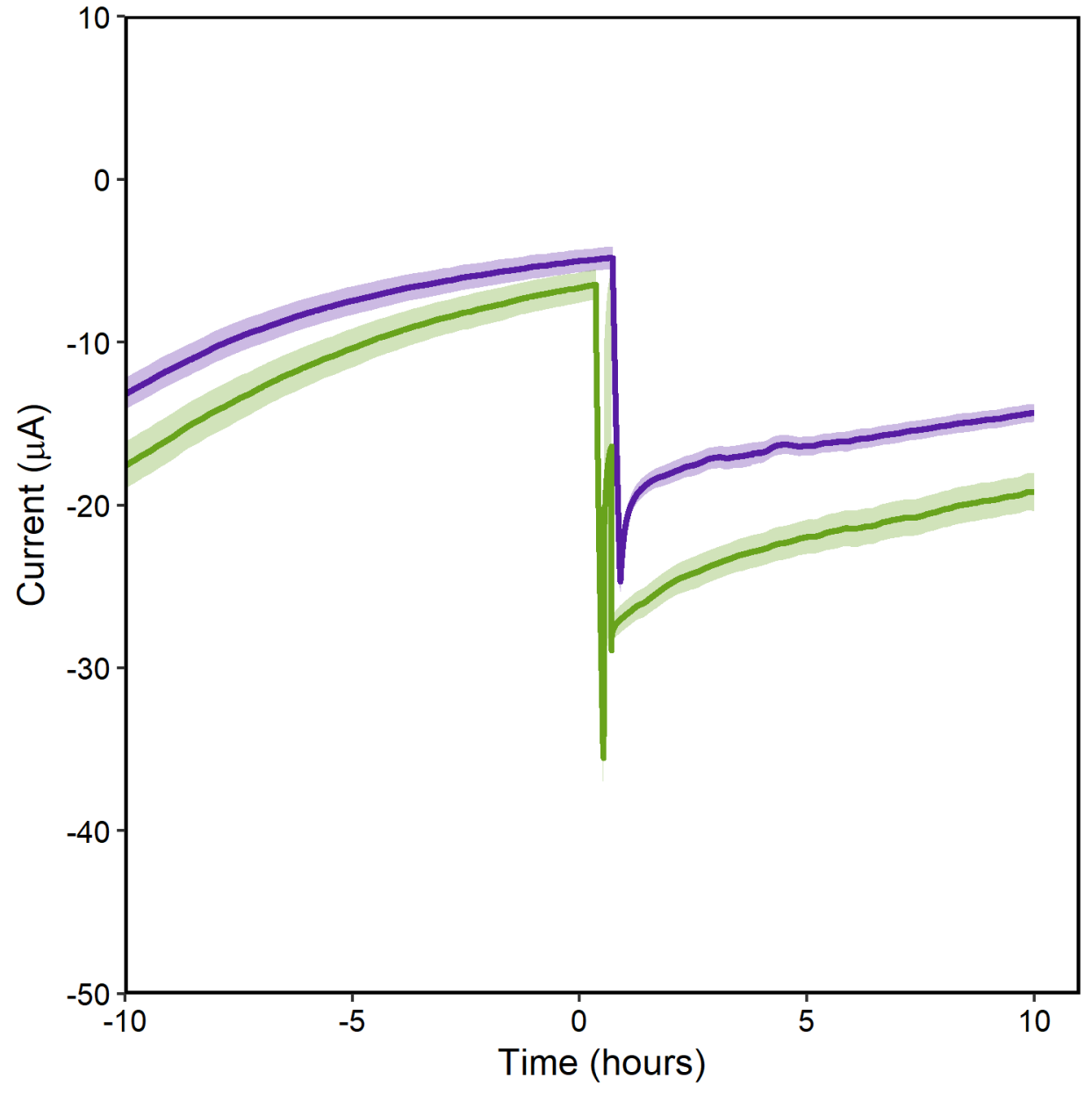

Figure 2. Cathodic current measurement during electron acceptor injection. Cathodic bioelectrochemical system. Time 0 represents acetoin injection. Current measured in bioelectrochemical systems containing cells grown with holo-PR are shown in green and those containing apo-PR are shown in purple. Each line represents the average of three replicates with standard error shown in transparent ribbons. 


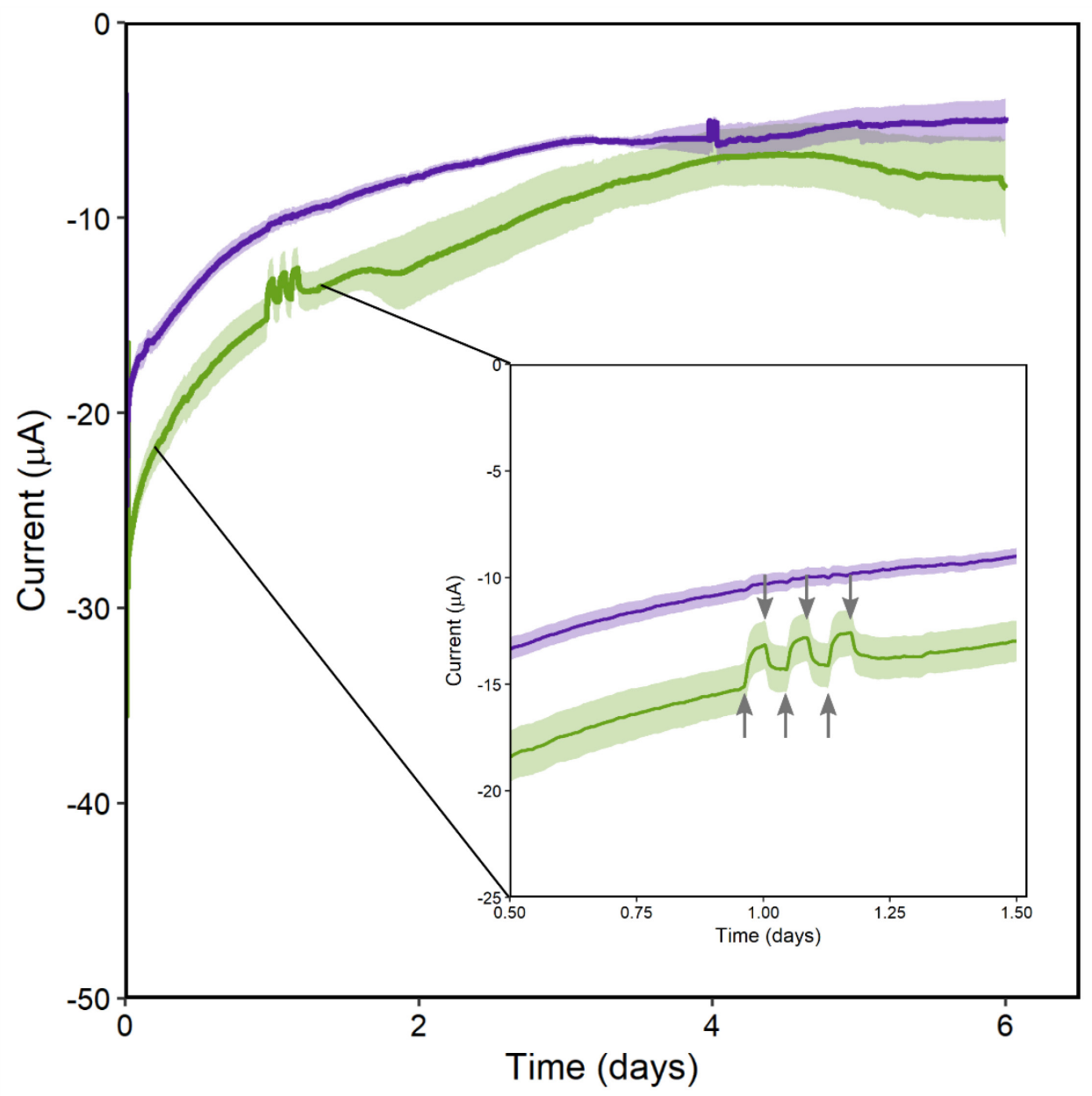

Figure 3. Response of cathodic current to green light. Current was measured in bioelectrochemical systems with electrodes poised at $-0.3 \mathrm{~V}_{\text {SHE }}$. Current shown was measured beginning at injection of acetoin (time 0 ). Current measured in reactors containing cells with

418 holo-PR are shown in green and those containing apo-PR are shown in purple. Inset graph shows current change due to removal or addition of green light. Lights were turned off for 3 one hour intervals beginning just before time $=1$ day. Each line represents the average of three replicates with standard error shown in transparent ribbons. 


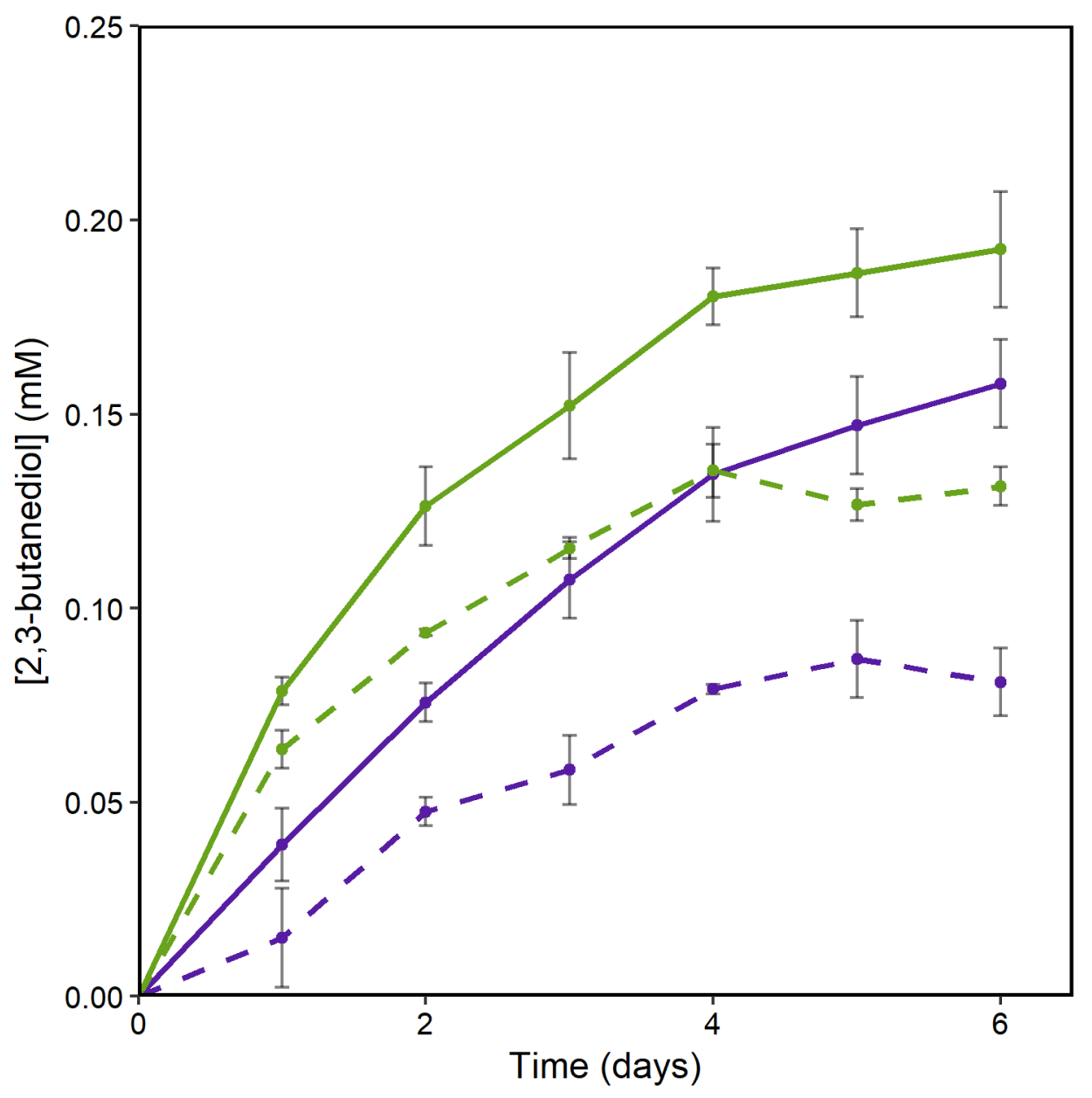

Figure 4. 2,3-butanediol accumulation increases when potential is applied to the working electrode. HPLC measurement of 2,3 butanediol concentration in bioelectrochemical systems over time. Samples taken from working electrode chambers with electrodes poised at $-0.3 \mathrm{~V}_{\text {SHE }}$ are shown in solid green and purple lines. Samples taken from bioelectrochemical systems disconnected from the potentiostat are shown in dashed green and purple lines. Samples from reactors containing cells with holo-PR are shown in green and those containing apo-PR are shown in purple. Each point represents the average of three replicates with standard error shown in error bars. 


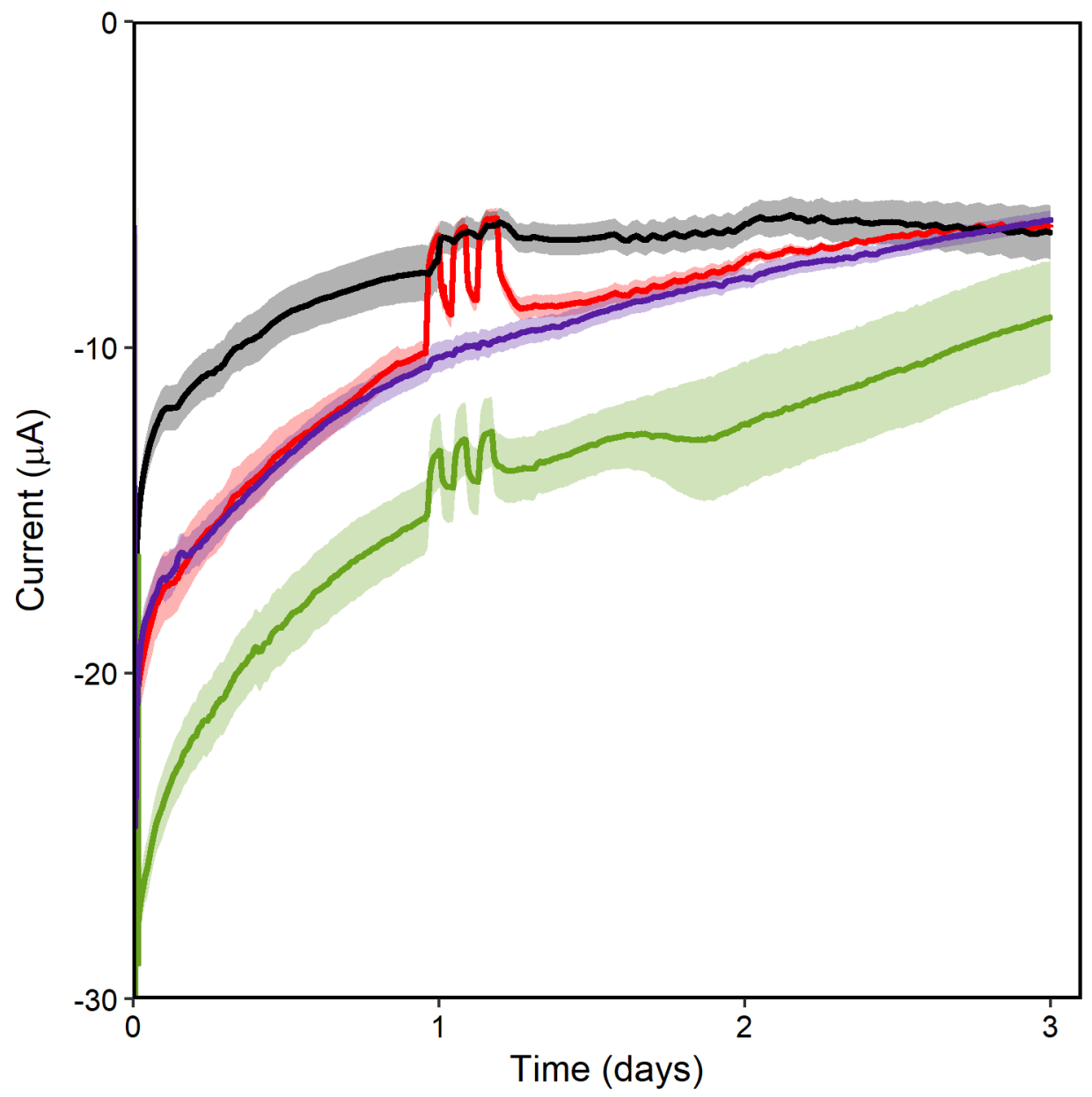

Figure 5. Both proteorhodopsin and butanediol dehydrogenase increase current. Current measured in bioelectrochemical systems containing cells expressing Bdh-PR with holo-PR are shown in green and those containing apo-PR are shown in purple. Current measured in reactors containing cells expressing only holo-PR are shown in red and those containing only apo-PR are shown in black. Current was measured in bioreactors with electrodes poised at $-0.3 \mathrm{~V}_{\text {SHE}}$. Current shown begins at injection of acetoin (time 0 ). Each line represents the average of three replicates with standard error shown in transparent ribbons. 

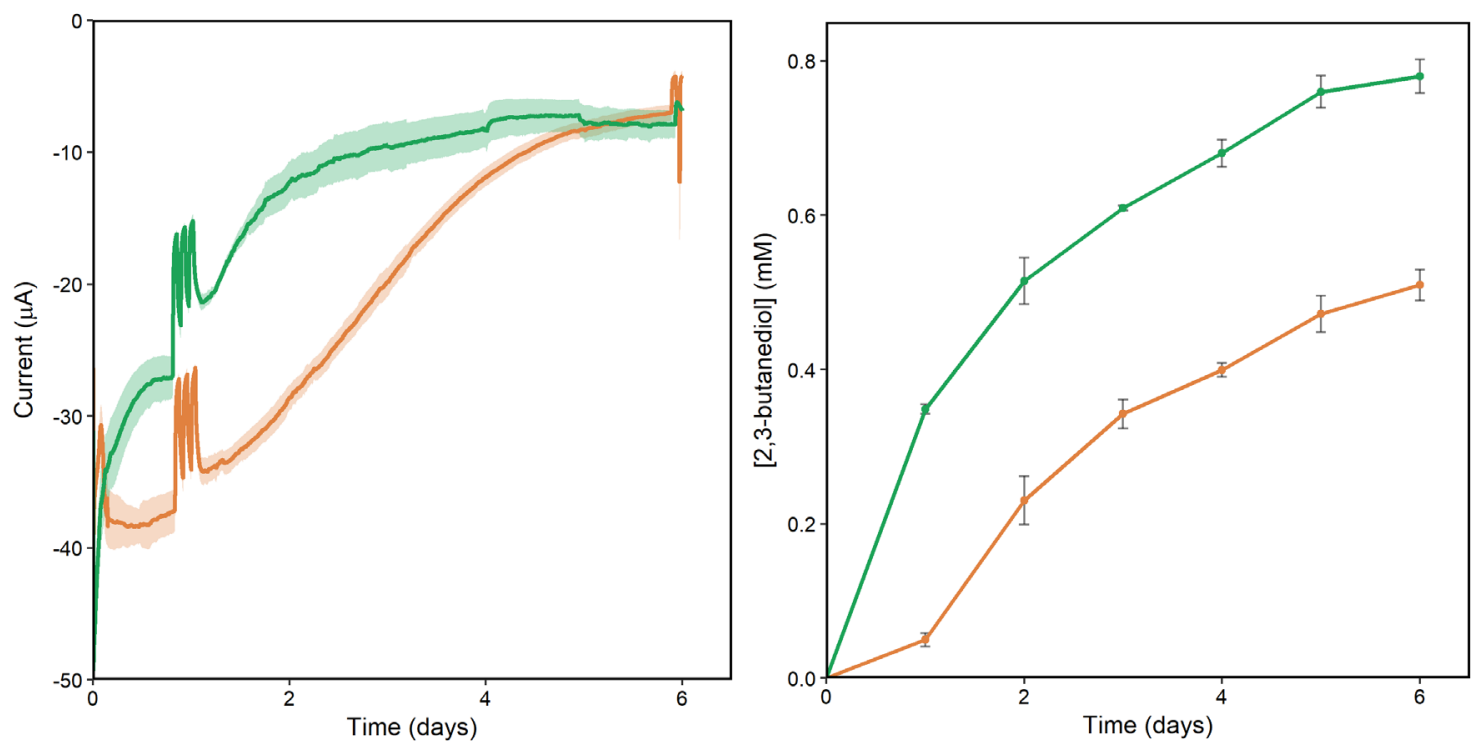

Figure 6. Removal of native hydrogenases decreases current and increases 2,3-butanediol production. (A) Current and (B) 2,3-butanediol accumulation observed in bioreactors containing cells expressing Bdh and holo-PR. The strain without hydrogenases is shown in dark green and the wild-type background is shown in orange. Data shown was measured beginning at injection of acetoin (time 0 ). Each point represents the average of three replicates with standard error shown in transparent ribbons or error bars. 


\section{References}

1. Rabaey K, Rozendal RA. 2010. Microbial electrosynthesis - revisiting the electrical route for microbial production. Nat Rev Microbiol 8:706-716.

2. Rosenbaum MA, Henrich AW. 2014. Engineering microbial electrocatalysis for chemical and fuel production. Curr Opin Biotechnol 29:93-98.

3. Nevin KP, Woodard TL, Franks AE, Summers ZM, Lovley DR. 2010. Microbial electrosynthesis: Feeding microbes electricity to convert carbon dioxide and water to multicarbon extracellular organic compounds. MBio 1:e00103-10.

4. Nevin KP, Hensley SA, Franks AE, Summers ZM, Ou J, Woodard TL, SnoeyenbosWest OL, Lovley DR. 2011. Electrosynthesis of organic compounds from carbon dioxide is catalyzed by a diversity of acetogenic microorganisms. Appl Environ Microbiol 77:2882-2886.

5. Ganigué R, Puig S, Batlle-Vilanova P, Balaguer MD, Colprim J, Mikkelsen M, Jørgensen M, Krebs FC, Haszeldine RS, Rabaey K, Rozendal RA, Nevin KP, Woodard TL, Franks AE, Summers ZM, Lovley DR, Marshall CW, Ross DE, Fichot EB, Norman RS, May HD, Marshall CW, Ross DE, Fichot EB, Norman RS, May HD, Sharma M, Aryal N, Sarma PM, Vanbroekhoven K, Lal B, Benetton XD, Pant D, Steinbusch KJJ, Hamelers HVM, Schaap JD, Kampman C, Buisman CJN, Eerten-Jansen MCAA Van, Heijne A Ter, Grootscholten TIM, Steinbusch KJJ, Sleutels THJA, Hamelers HVM, Buisman CJN, Dwidar M, Park J-Y, Mitchell RJ, Sang B-I, Sánchez P, Ganigue R, Bañeras L, Colprim J, Daniell J, Köpke M, Simpson SD, Gössner AS, Picardal F, Tanner RS, Drake HL, Thauer RK, Jungermann K, Decker K, Pi PPH, Agler MT, Wrenn BA, Zinder SH, Angenent LT, Batlle-Vilanova P, Puig S, Gonzalez-Olmos R, Vilajeliu-Pons A, Bañeras L, Balaguer MD, Colprim J, Jeremiasse AW, Hamelers HVM, Buisman CJN, Eerten-jansen MCAA Van, Heijne A Ter, Buisman CJN, Hamelers HVM, Bechthold I, Bretz K, Kabasci S, Kopitzky R, Springer A, Andersen SJ, Hennebel T, Gildemyn S, Coma M, Desloover J, Berton J, Tsukamoto J, Stevens C V., Rabaey K, Tanner RS, Miller LM, Yang D. 2015. Microbial electrosynthesis of butyrate from carbon dioxide. Chem Commun 51:3235-3238.

6. Patil SA, Arends JBA, Vanwonterghem I, van Meerbergen J, Guo K, Tyson GW, Rabaey K. 2015. Selective enrichment establishes a stable performing community for microbial electrosynthesis of acetate from $\mathrm{CO}_{2}$. Environ Sci Technol 49:8833-8843.

7. Park DH, Zeikus JG. 1999. Utilization of electrically reduced neutral red by Actinobacillus succinogenes: Physiological function of neutral red in membrane-driven fumarate reduction and energy conservation. J Bacteriol 181:2403-2410.

8. Park DH, Laivenieks M, Guettler M V, Jain MK, Zeikus JG. 1999. Microbial utilization of electrically reduced neutral red as the sole electron donor for growth and metabolite production. Appl Environ Microbiol 65:2912-7.

9. Drake HL, Gößner AS, Daniel SL. 2008. Old acetogens, new light, p. 100-128. In Annals of the New York Academy of Sciences.

10. Müller V. 2003. Energy Conservation in Acetogenic Bacteria. Appl Environ Microbiol.

11. Ueki T, Nevin KP, Woodard TL, Lovley DR. 2014. Converting carbon dioxide to butyrate with an engineered strain of Clostridium ljungdahlii. MBio $\mathbf{5}$.

12. Schiel-Bengelsdorf B, Dürre P. 2012. Pathway engineering and synthetic biology using acetogens. FEBS Lett 586:2191-2198. 
13. Harrington TD, Tran VN, Mohamed A, Renslow R, Biria S, Orfe L, Call DR, Beyenal H. 2015. The mechanism of neutral red-mediated microbial electrosynthesis in Escherichia coli: menaquinone reduction. Bioresour Technol 192:689-95.

14. Harrington TD, Mohamed A, Tran VN, Biria S, Gargouri M, Park J-J, Gang DR, Beyenal H. 2015. Neutral red-mediated microbial electrosynthesis by Escherichia coli, Klebsiella pneumoniae, and Zymomonas mobilis. Bioresour Technol 195:57-65.

15. Le QAT, Kim HG, Kim YH. 2018. Electrochemical synthesis of formic acid from CO2 catalyzed by Shewanella oneidensis MR-1 whole-cell biocatalyst. Enzyme Microb Technol 116:1-5.

16. Batlle-Vilanova P, Puig S, Gonzalez-Olmos R, Balaguer MD, Colprim J. 2016. Continuous acetate production through microbial electrosynthesis from $\mathrm{CO} 2$ with microbial mixed culture. J Chem Technol Biotechnol 91:921-927.

17. Jourdin L, Grieger T, Monetti J, Flexer V, Freguia S, Lu Y, Chen J, Romano M, Wallace GG, Keller J. 2015. High acetic acid production rate obtained by microbial electrosynthesis from carbon dioxide. Environ Sci Technol 49:13566-13574.

18. Jourdin L, Freguia S, Flexer V, Keller J. 2016. Bringing high-rate, $\mathrm{CO}_{2}$-based microbial electrosynthesis closer to practical implementation through improved electrode design and operating conditions. Environ Sci Technol 50:1982-1989.

19. Batlle-Vilanova P, Ganigué R, Ramió-Pujol S, Bañeras L, Jiménez G, Hidalgo M, Balaguer MD, Colprim J, Puig S. 2017. Microbial electrosynthesis of butyrate from carbon dioxide: Production and extraction. Bioelectrochemistry 117:57-64.

20. Bajracharya S, ter Heijne A, Dominguez Benetton X, Vanbroekhoven K, Buisman CJN, Strik DPBTB, Pant D. 2015. Carbon dioxide reduction by mixed and pure cultures in microbial electrosynthesis using an assembly of graphite felt and stainless steel as a cathode. Bioresour Technol 195:14-24.

21. Coursolle D, Gralnick JA. 2012. Reconstruction of extracellular respiratory pathways for iron(III) reduction in Shewanella oneidensis strain MR-1. Front Microbiol 3:56.

22. Coursolle D, Baron DB, Bond DR, Gralnick JA. 2010. The Mtr respiratory pathway is essential for reducing flavins and electrodes in Shewanella oneidensis. J Bacteriol 192:467-474.

23. Clarke TA, Edwards MJ, Gates AJ, Hall A, White GF, Bradley J, Reardon CL, Shi L, Beliaev AS, Marshall MJ, Wang Z, Watmough NJ, Fredrickson JK, Zachara JM, Butt JN, Richardson DJ. 2011. Structure of a bacterial cell surface decaheme electron conduit. Proc Natl Acad Sci 108:9384-9389.

24. Myers CR, Myers JM. 2002. MtrB Is required for proper incorporation of the cytochromes OmcA and OmcB into the outer membrane of Shewanella putrefaciens MR1. Appl Environ Microbiol 68:5585-5594.

25. Liu Y, Wang Z, Liu J, Levar C, Edwards MJ, Babauta JT, Kennedy DW, Shi Z, Beyenal H, Bond DR, Clarke TA, Butt JN, Richardson DJ, Rosso KM, Zachara JM, Fredrickson JK, Shi L. 2014. A trans-outer membrane porin-cytochrome protein complex for extracellular electron transfer by Geobacter sulfurreducens PCA. Environ Microbiol Rep 6:776-785.

26. Marritt SJ, Lowe TG, Bye J, McMillan DGG, Shi L, Fredrickson J, Zachara J, Richardson DJ, Cheesman MR, Jeuken LJC, Butt JN. 2012. A functional description of CymA, an electron-transfer hub supporting anaerobic respiratory flexibility in Shewanella. Biochem J 444:465-474. 
27. Fredrickson JK, Romine MF, Beliaev AS, Auchtung JM, Driscoll ME, Gardner TS, Nealson KH, Osterman AL, Pinchuk G, Reed JL, Rodionov DA, Rodrigues JLM, Saffarini DA, Serres MH, Spormann AM, Zhulin IB, Tiedje JM. 2008. Towards environmental systems biology of Shewanella. Nat Rev Microbiol 6:592-603.

28. TerAvest MA, Ajo-Franklin CM. 2015. Transforming exoelectrogens for biotechnology using synthetic biology. Biotechnol Bioeng 113:687-697.

29. Ross DE, Flynn JM, Baron DB, Gralnick JA, Bond DR. 2011. Towards electrosynthesis in Shewanella: Energetics of reversing the Mtr pathway for reductive metabolism. PLoS One 6:e16649.

30. Rowe AR, Rajeev P, Jain A, Pirbadian S, Okamoto A, Gralnick JA, El-Naggar MY, Nealson KH. 2018. Tracking electron uptake from a cathode into Shewanella cells: implications for energy acquisition from solid-substrate electron donors. MBio 9.

31. Pinchuk GE, Hill EA, Geydebrekht O V, De Ingeniis J, Zhang X, Osterman A, Scott JH, Reed SB, Romine MF, Konopka AE, Beliaev AS, Fredrickson JK, Reed JL. 2010. Constraint-based model of Shewanella oneidensis MR-1 metabolism: a tool for data analysis and hypothesis generation. PLoS Comput Biol 6:e1000822.

32. Spero MA, Aylward FO, Currie CR, Donohue TJ. 2015. Phylogenomic analysis and predicted physiological role of the proton-translocating NADH:quinone oxidoreductase (complex I) across bacteria. MBio 6:e00389-15-.

33. Johnson ET, Baron DB, Naranjo B, Bond DR, Schmidt-Dannert C, Gralnick JA. 2010. Enhancement of survival and electricity production in an engineered bacterium by light-driven proton pumping. Appl Environ Microbiol 76:4123-4129.

34. Hunt KA, Flynn JM, Naranjo B, Shikhare ID, Gralnick JA. 2010. Substrate-level phosphorylation is the primary source of energy conservation during anaerobic respiration of Shewanella oneidensis strain MR-1. J Bacteriol 192:3345-3351.

35. Kreuzer HW, Hill EA, Moran JJ, Bartholomew RA, Yang H, Hegg EL. 2014. Contributions of the [NiFe]- and [FeFe]-hydrogenase to $\mathrm{H}_{2}$ production in Shewanella oneidensis MR-1 as revealed by isotope ratio analysis of evolved $\mathrm{H}_{2}$. FEMS Microbiol Lett 352:18-24.

36. Pinchuk GE, Geydebrekht O V., Hill EA, Reed JL, Konopka AE, Beliaev AS, Fredrickson JK. 2011. Pyruvate and lactate metabolism by Shewanella oneidensis MR-1 under fermentation, oxygen limitation, and fumarate respiration conditions. Appl Environ Microbiol 77:8234-8240.

37. Blanchet E, Duquenne F, Rafrafi Y, Etcheverry L, Erable B, Bergel A. 2015. Importance of the hydrogen route in up-scaling electrosynthesis for microbial CO2 reduction. Energy Environ Sci 8:3731-3744.

38. Deutzmann JS, Sahin M, Spormann AM. 2015. Extracellular enzymes facilitate electron uptake in biocorrosion and bioelectrosynthesis. MBio 6.

39. Meshulam-Simon G, Behrens S, Choo AD, Spormann AM. 2007. Hydrogen metabolism in Shewanella oneidensis MR-1. Appl Environ Microbiol 73:1153-1165.

40. Jensen HM, Albers AE, Malley KR, Londer YY, Cohen BE, Helms BA, Weigele P, Groves JT, Ajo-Franklin CM. 2010. Engineering of a synthetic electron conduit in living cells. Proc Natl Acad Sci 107:19213-19218.

41. Rowe AR, Rajeev P, Jain A, Pirbadian S, Okamotao A, Gralnick JA, El-Naggar MY, Nealson K. 2017. Tracking electron uptake from a cathode into Shewanella cells: implications for generating maintenance energy from solid substrates. bioRxiv. 
42. Pinchuk GE, Hill EA, Geydebrekht O V., de Ingeniis J, Zhang X, Osterman A, Scott JH, Reed SB, Romine MF, Konopka AE, Beliaev AS, Fredrickson JK, Reed JL. 2010. Constraint-based model of Shewanella oneidensis MR-1 metabolism: A tool for data analysis and hypothesis generation. PLoS Comput Biol 6:1-8.

43. Duhl, K. L., Tefft, N. M., \& TerAvest MA. 2018. Shewanella oneidensis MR-1 utilizes both sodium- and proton-pumping NADH dehydrogenases during aerobic growth. Appl Environ Microbiol.

44. Einhauer A, Jungbauer A. 2001. The FLAG ${ }^{\mathrm{TM}}$ peptide, a versatile fusion tag for the purification of recombinant proteins. J Biochem Biophys Methods 49:455-465.

45. Salis HM. 2011. The ribosome binding site calculator. Methods Enzymol 498:19-42.

46. De Lorenzo V, Herrero M, Jakubzik U, Timmis KN. 1990. Mini-Tn5 transposoon derivatives for insertion mutagenesis, promoter probing, and chromosomal insertion of cloned DNA in gram-negative eubacteria. J Bacteriol 172:6568-6572.

47. Fuhrman JA, Schwalbach MS, Stingl U. 2008. Proteorhodopsins: An array of physiological roles? Nat Rev Microbiol 6:488-494.

48. Wickham H. 2009. ggplot2 Elegant Graphics for Data AnalysisMedia.

49. Wickham H. 2007. Reshaping data with the reshape package. J Stat Softw 21:1-20.

50. Wickham H, Francois R. 2015. dplyr: A Grammar of Data Manipulation. R Packag version 0423.

51. Ulrich J. 2017. TTR: Technical Trading Rules. R Packag version 023-2.

52. Saltikov CW, Newman DK. 2003. Genetic identification of a respiratory arsenate reductase. Proc Natl Acad Sci U S A 100:10983-10988.

53. Myers CR, Nealson KH. 1988. Bacterial manganese reduction and growth with manganese oxide as the sole electron acceptor. Science 240:1319-1321.

54. Meshulam-Simon G, Behrens S, Choo AD, Spormann AM. 2007. Hydrogen metabolism in Shewanella oneidensis MR-1. Appl Environ Microbiol 73:1153-1165.

55. Kreuzer HW, Hill EA, Moran JJ, Bartholomew RA, Yang H, Hegg EL. 2014. Contributions of the [NiFe]- and [FeFe]-hydrogenase to $\mathrm{H} 2$ production in Shewanella oneidensis MR-1 as revealed by isotope ratio analysis of evolved H(2). FEMS Microbiol Lett 352:18-24.

56. Yazynin SA, Deyev SM, Jucovič M, Hartley RW. 1996. A plasmid vector with positive selection and directional cloning based on a conditionally lethal gene. Gene 169:131-132.

57. Beja O, Aravind L, Koonin E V., Suzuki MT, Hadd A, Nguyen LP, Jovanovich SB, Gates CM, Feldman RA, Spudich JL, Spudich EN, DeLong EF. 2000. Bacterial rhodopsin: Evidence for a new type of phototrophy in the sea. Science 1902-1906. 